\title{
Non-linear intensification of Sahel rainfall as a possible dynamic response to future warming
}

\author{
Jacob Schewe $^{1}$ and Anders Levermann ${ }^{1,2,3}$ \\ ${ }^{1}$ Potsdam Institute for Climate Impact Research, Potsdam, Germany \\ ${ }^{2}$ Institute of Physics, Potsdam University, Potsdam, Germany \\ ${ }^{3}$ Lamont-Doherty Earth Observatory, Columbia University, New York, USA \\ Correspondence to: Jacob Schewe (jacob.schewe@pik-potsdam.de)
}

Received: 18 November 2016 - Discussion started: 30 November 2016

Revised: 1 June 2017 - Accepted: 13 June 2017 - Published: 5 July 2017

\begin{abstract}
Projections of the response of Sahel rainfall to future global warming diverge significantly. Meanwhile, paleoclimatic records suggest that Sahel rainfall is capable of abrupt transitions in response to gradual forcing. Here we present climate modeling evidence for the possibility of an abrupt intensification of Sahel rainfall under future climate change. Analyzing 30 coupled global climate model simulations, we identify seven models where central Sahel rainfall increases by 40 to $300 \%$ over the 21 st century, owing to a northward expansion of the West African monsoon domain. Rainfall in these models is non-linearly related to sea surface temperature (SST) in the tropical Atlantic and Mediterranean moisture source regions, intensifying abruptly beyond a certain SST warming level. We argue that this behavior is consistent with a self-amplifying dynamicthermodynamical feedback, implying that the gradual increase in oceanic moisture availability under warming could trigger a sudden intensification of monsoon rainfall far inland of today's core monsoon region.
\end{abstract}

\section{Introduction}

The Sahel is a wide semi-arid belt spanning the African continent south of the Sahara, and is home to a large population strongly reliant on agriculture (Sissoko et al., 2010). Its climate has been characterized by devastating droughts, such as in the 1970s and 80s (Folland et al., 1986; Zeng, 2003), alternating with episodes of abundant rainfall such as in the 1930s and 50s, and even destructive rain and flood events such as in 2007 (Tschakert et al., 2010; Tarhule, 2005). The 1970s/80s drought, which resulted in persistent food shortage and widespread famine (Nicholson, 2013), has been attributed to anthropogenic reflective aerosols as well as variations in Atlantic sea surface temperature (SST), which may have been partly human-induced and partly due to natural variability (Giannini et al., 2003; Biasutti and Giannini, 2006). Rainfall has partially recovered more recently (Lebel et al., 2009), a trend that has been attributed both to the direct radiative effect of anthropogenic greenhouse gases (Dong and Sutton, 2015) and to SST warming, especially in the Mediterranean (Park et al., 2016).

While coupled climate models generally capture the temporal pattern of the 1970s/80s drought (Biasutti and Giannini, 2006), most simulations from the recent Coupled Model Intercomparison Project phase 5 (CMIP5) underestimate its magnitude (Biasutti, 2013). At the same time, projections of future rainfall changes diverge substantially across the models (Power et al., 2012). The CMIP5 multi-model mean was shown to exhibit only a slight increase in overall Sahel rainfall (Fontaine et al., 2011; Biasutti, 2013), with a wetting trend over the central and eastern Sahel and drying over the westernmost part, under the highest representative concentration pathway (van Vuuren et al., 2011), RCP8.5. Individually, some of the models project a much stronger rainfall increase, while others even project an overall decrease.

This uncertainty in future projections raises questions about potential mechanisms of change that may be present in some models but not others, and that may be responsible for the large differences between models. In particular, pa- 


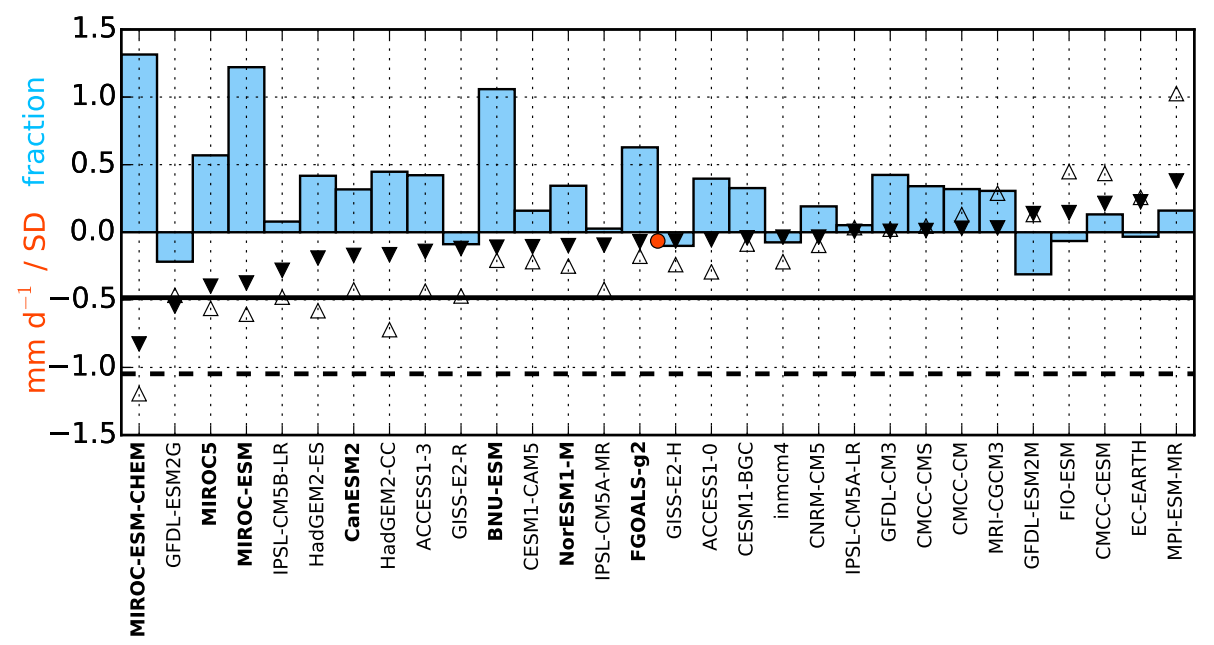

Figure 1. Past and future Sahel summer rainfall in CMIP5 coupled climate models. Blue bars show the change in central and eastern Sahel average summer rainfall $\left(0-30^{\circ} \mathrm{E}, 10-20^{\circ} \mathrm{N}\right.$; July-September) by the end of the century (2071-2095) under RCP8.5 compared to the 19011999 average, as a fraction of that average. The seven models investigated in detail in this paper (Wet7 subset) are marked in bold. Filled triangles show the difference (drought minus non-drought) between the 1970-1989 drought period and the rest of the observational period ("non-drought", 1901-1969 and 1990-2009), in mm day ${ }^{-1}$. Open triangles show the same difference divided by the standard deviation of the non-drought period, in units of standard deviations. The solid and dashed horizontal lines show the respective observed values (CRU TS3.1; Harris et al., 2014). The orange circle indicates the median deviation from the observed drought-non-drought difference across the model ensemble; i.e., models shown to the left of this point are closer than average to the observed value.

leoclimatic records suggest that Sahel rainfall is capable of abrupt transitions in response to gradual forcing (DeMenocal et al., 2000; McGee et al., 2013), and theoretical studies have demonstrated that such a non-linear response can in principle arise from internal monsoon dynamics (Levermann et al., 2009; Seshadri, 2016). In this study, we examine Sahel rainfall in state-of-the-art climate model simulations and show that in those models that exhibit the strongest rainfall increase, this increase is non-linearly related to the SST warming in the tropical North Atlantic and Mediterranean moisture source regions.

We argue that this behavior is consistent with the theory and paleoclimatic evidence mentioned above. Considering that this non-linear rainfall response may be more pronounced in some models than in others may contribute to understanding the differences between the models' future projections.

\section{Methods and results}

We investigated Sahel rainfall in 30 Coupled Model Intercomparison Project phase 5 (CMIP5) global climate models under RCP8.5 (see Appendix A). Three models (MIROCESM-CHEM, MIROC-ESM, BNU-ESM) project an increase of over $100 \%$ in average summer (July-September) rainfall across the central and eastern Sahel by the end of the 21st century (Fig. 1). Some other models (notably FGOALS-g2, MIROC5, CanESM2, NorESM1-M) project slightly smaller rainfall increases but with similar patterns as the three wettest models: a pronounced rainfall increase north and east of the present core monsoon region (Fig. 2; notice that while CanESM2 has only a moderate wetting trend over the central Sahel region analyzed in Fig. 1, it shows a strong rainfall increase in the eastern Sahel). This is in contrast to the majority of models, which do not show a marked rainfall increase outside the present-day monsoon region (Supplement figures). We select the above-mentioned seven models hereafter referred to as the "Wet7" subset - for further investigation in order to elucidate possible mechanisms behind the strong rainfall increase in presently dry regions. We note that the Wet7 can largely account for the positive rainfall trend that has been found in the CMIP5 ensemble as a whole (see Roehrig et al., 2013; Park et al., 2015): the Wet7 multi-model mean shows a doubling of average summer rainfall by 2100 (Fig. 3). In contrast, the mean over the 23 other models exhibits only a weak wetting trend of less than $20 \%$; trends in the individual models are small and some models even show a drying trend.

Although we focus here on the future projections, we also note that the Wet7 models perform better than average in reproducing the magnitude of the 1970-1989 drought period, the three MIROC models especially being very close to observed values (orange lines in Fig. 1, and inset in Fig. 3). This observation is consistent with a more comprehensive analysis of the CMIP5 models for the historical period by Biasutti (2013), which found that past multi-decadal variability is underestimated by all except a few models, one MIROC model among them. It may serve as an additional motivation to fur- 

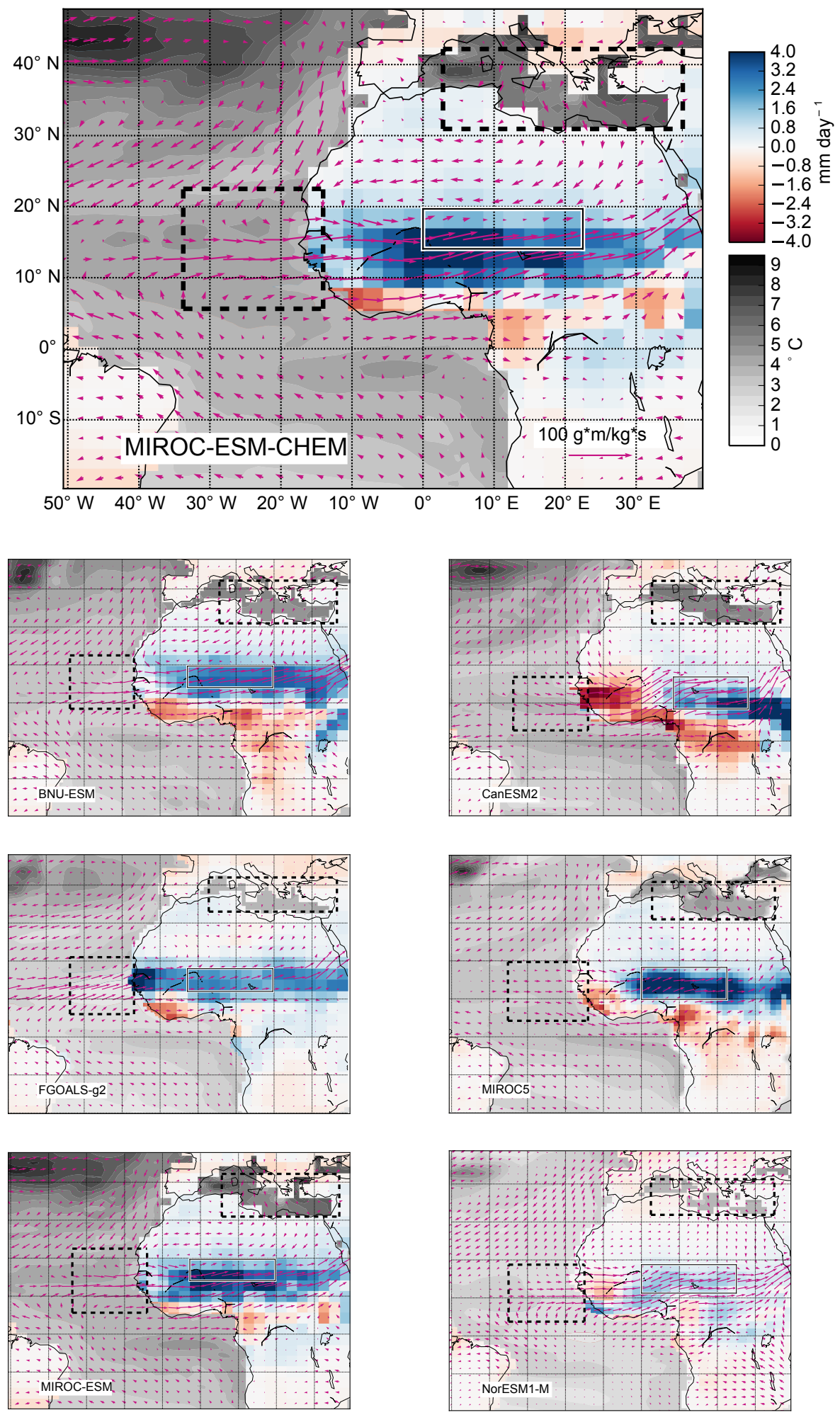

Figure 2. Simulated changes in Sahel summer climate under RCP8.5 in the Wet7 models. For each model the differences in July-September rainfall (colors), sea surface temperature (SST, greyscale; contour spacing is $0.5 \mathrm{~K}$ ), and moisture flux integrated vertically over the three bottom-most pressure levels (1000, 925, and 850 mbar; arrows) are shown between the 20th century (1900-1999) and the end of the 21st century (2070-2099). Solid (dashed) boxes show the regions over which rainfall (SST) differences are averaged for Fig. 7 and the following figures. The color scale, vector scale, and coordinate labels of the top panel apply to all panels. 


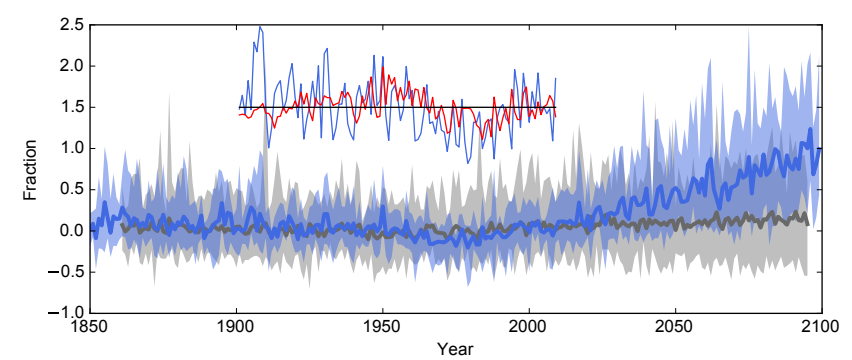

Figure 3. Sahel summer rainfall in two model subsets and in observations. Shading shows the envelopes (minimum and maximum among models) of Sahel summer rainfall $\left(0-30^{\circ} \mathrm{E}, 10-20^{\circ} \mathrm{N}\right.$; JulySeptember) in the Wet7 subset (blue) and in 23 other CMIP5 models (grey) under historical forcing and the RCP8.5 greenhouse gas concentration scenario. Shown is the deviation from the 1900-1999 average, as a fraction of that average. The thick lines indicate the averages of each set of models. Data between 1850 and 1860 and between 2095 and 2100 were unavailable for some of the models; therefore, the grey line and shading only extend from 1860 to 2095. The inset shows the CRU TS3.1 observational data set covering 1901-2009 (red) and the corresponding portion of the MIROCESM-CHEM simulation (blue), in the same units as the other data but offset by 1.5 in the vertical for clarity.

ther study the future projections by these models, which we do in the following.

We point out, however, that there is much variation among the Wet7 models themselves in terms of past and projected rainfall changes, and the dynamical features discussed below may be more or less developed in different models. We use the wettest model, MIROC-ESM-CHEM, to illustrate our discussion and show the other six models as evidence that our findings are not exclusive to just one model.

The seasonal distribution of the rainfall change in the Wet7 shows a clear monsoonal shape, despite considerable spread in its magnitude (Fig. 3).

Generally, the rainfall increase occurs over a broad region between 10 and $20^{\circ} \mathrm{N}$, i.e., extending into today's Sahara (Fig. 4). Conversely, rainfall decreases somewhat in the more humid regions around the Gulf of Guinea and the west coast. This pattern corresponds to an inland shift compared to the present-day rainfall regime. At the same time, the nearsurface, southwesterly winds intensify in the northern and eastern parts of the Sahel, near the positive rainfall anomaly, while they do not change much near the coast (Fig. 5).

This suggests that the rainfall increase is not simply a consequence of thermodynamic changes (higher water-holding capacity of warmer air) but goes together with a shift in West African monsoon circulation dynamics.

Sahel rainfall has been linked to Atlantic as well as Mediterranean SSTs via evaporation rate and moisture supply (e.g., Giannini et al., 2003; Rowell, 2003). In order to examine temporal patterns of rainfall and SST change more closely, we average each model's summer rainfall over a rectangular subregion of the Sahel (solid boxes in Figs. 4 and 5).

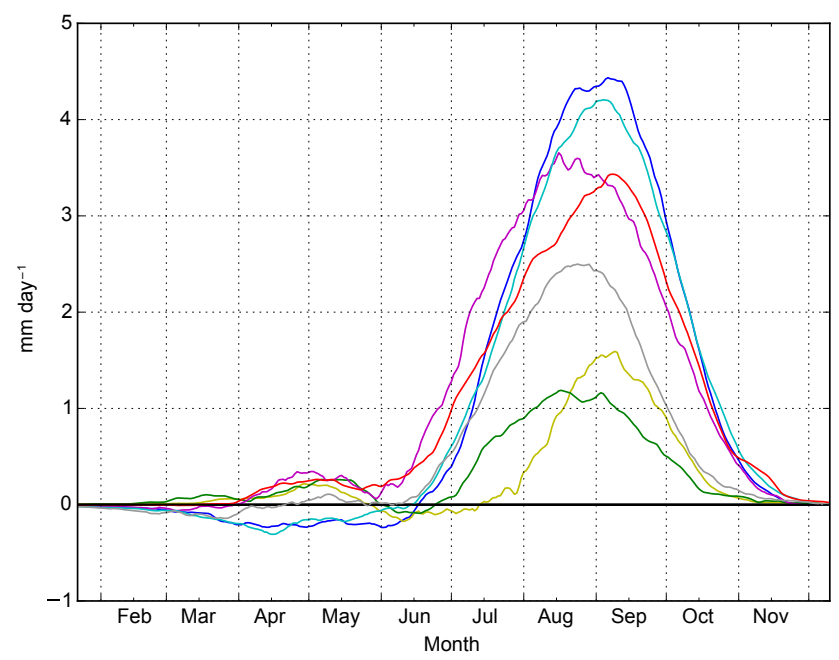

Figure 4. Change (future minus past) in average Sahel $\left(0-30^{\circ} \mathrm{E}\right.$, $10-20^{\circ} \mathrm{N}$ ) daily precipitation between the end of the 20th century (1970-1999) and the end of the 21st century (2070-2099) in the Wet7 models. All time series filtered with a 6-week running mean.

The subregions are chosen to encompass an area where the rainfall increase is substantial in both absolute (Fig. 4) and relative terms (Fig. 5), and to be similar in size and location across the different models' grids (except for CanESM2, where the rainfall increase is located further east than in the other models). Thus, the subregions are generally located northward of the present-day core monsoon regions, which also see rainfall increases but less pronounced in relative terms.

Similarly, we identify for each model one region in the tropical North Atlantic Ocean and one in the Mediterranean Sea (dashed boxes in Fig. 4) as the main sources of additional moisture influx into the Sahel, based on the lowertroposphere moisture flux changes (arrows in Fig. 4).

Moisture influx from both sources into North Africa is projected to increase in the Wet7 models (Fig. 2). However, moisture flux from the Atlantic into the Sahel subregion increases more strongly than from the Mediterranean by the end of the 21st century (Figs. 2 and 6). Moreover, only the Atlantic branch is accompanied by an increase in near-surface wind speed (Fig. 5). Thus, while the increased moisture import from the Mediterranean appears to be due to higher SST and evaporation alone, increased wind speed further amplifies moisture import from the Atlantic - a mechanism already proposed by Rowell (2003).

Sahel rainfall generally increases as the surface of the oceanic moisture source regions warms (Figs. 7 and 8). But this relation is not linear. Rainfall shows little response to SST changes within a range of approx. $1^{\circ} \mathrm{C}$ around the present-day value; however, when SST increases beyond this point, rainfall shifts abruptly to a stronger level, where it then keeps increasing as SST rises further. Given the convex shape of the temperature forcing over time, the abruptness of the 

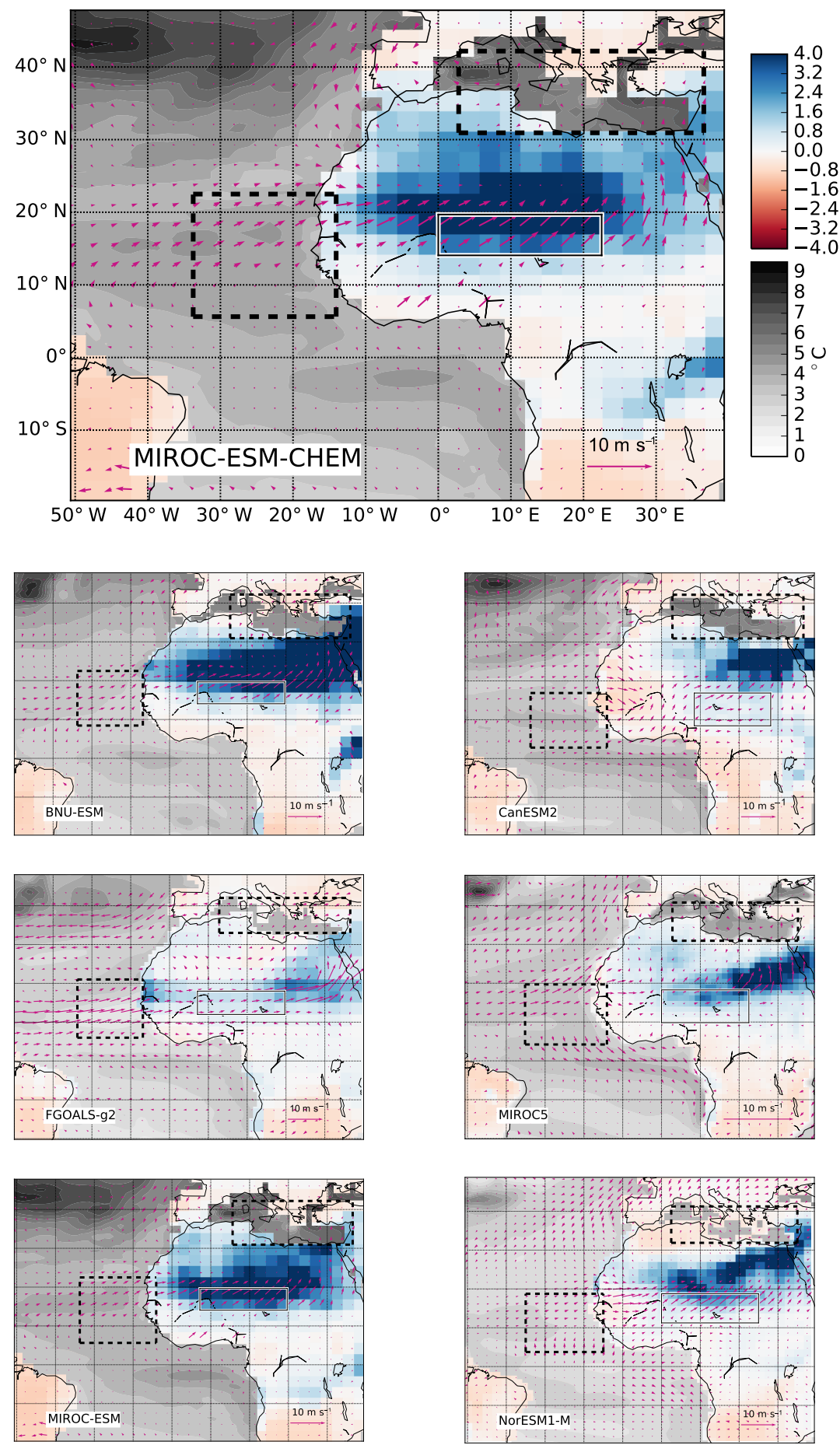

Figure 5. As Fig. 2, but colors show relative (rather than absolute) rainfall differences, in multiples of the reference value, and arrows show changes in near-surface winds (850 mbar winds for FGOALS-g2, where near-surface wind speed was not available).

rainfall response is expected to be less apparent in the time domain; nonetheless, rainfall appears relatively stable over the historical period, before it begins increasing strongly in the 21st century (Fig. 9).
Numerous paleoclimatic reconstructions reveal abrupt shifts in monsoon systems in Asia (Gupta et al., 2003; Wang et al., 2008) and Africa (DeMenocal et al., 2000; McGee et al., 2013; Weldeab et al., 2007) before and throughout the Holocene. In those cases, external forcing through changes 

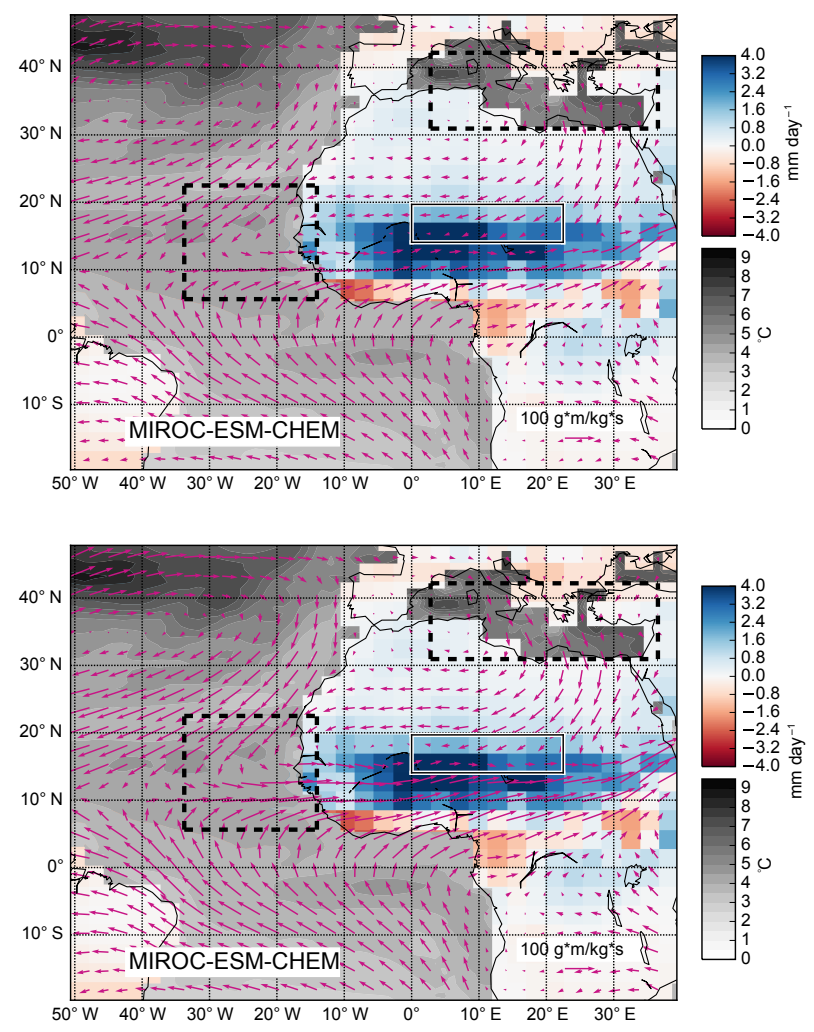

Figure 6. As in the top panel in Fig. 2 but showing absolute moisture flux in the 20th century (1900-1999, top) and the end of the 21 st century (2070-2099, bottom).

in solar insolation was much more gradual than that associated with modern anthropogenic climate change. A physical mechanism has been proposed to explain such abrupt shifts in large-scale monsoon rainfall in response to gradual forcing (Levermann et al., 2009, 2016):

While the summer monsoon circulation is initiated by differential warming of land and ocean in spring, it is latent heat release from precipitation that maintains the land-sea atmospheric temperature contrast throughout the summer and thus drives the monsoon winds into the continental interior. The monsoon winds in turn supply the moisture necessary to maintain precipitation. Summer monsoon rainfall is thus powered by a positive feedback between moisture inflow and atmospheric heating. This positive moisture-advection feedback gives rise to a threshold behavior with respect to external quantities that govern the energy budget of the monsoon; in particular, in this simplified theory, there is a minimum atmospheric humidity in the oceanic moisture source region below which such a monsoon circulation cannot be maintained (Schewe et al., 2012).

This framework has been used to explain abrupt variations in monsoon strength documented in Asian speleothem (Schewe et al., 2012) and pollen records (Herzschuh et al., 2014) but has not yet been applied to modern monsoon systems. We suggest that it is also useful for understanding the
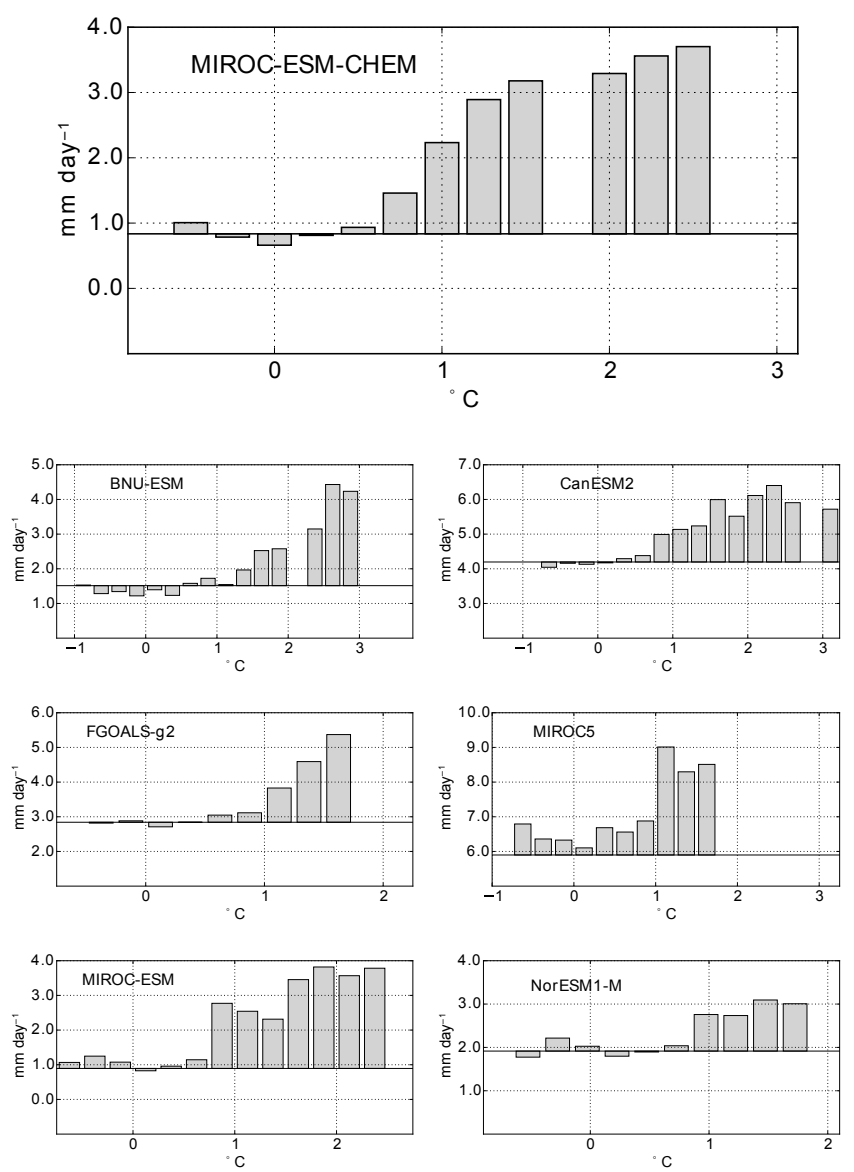

Figure 7. Median Sahel July-September rainfall for different intervals of tropical North Atlantic SST change (interval width $0.25^{\circ} \mathrm{C}$ ), including all data between 1850 and 2100. Bars illustrate the deviation from the 1900-1999 rainfall average (horizontal black line), and SST change is also relative to the 1900-1999 average. Bars are only shown if at least 5 years fall into the respective temperature interval. Rainfall and SST are averaged over the corresponding boxes shown in Figs. 2 and 5.

projected Sahel rainfall changes in the Wet7 models. Today, the West African monsoon is most active between the Gulf of Guinea coast and the southern edge of the Sahel (Nicholson, 2013). Rainfall declines towards the continental interior, and while central and eastern Sahel rainfall still exhibits a clear seasonality, it is relatively weak and erratic (compared to, for example, the Indian monsoon with its intense rainfall throughout much of the subcontinent). An increase in evaporation due to ocean warming in the tropical North Atlantic and the Mediterranean increases moisture availability. Once atmospheric humidity exceeds the monsoon threshold even in the more continental parts of the Sahel, the moistureadvection feedback can amplify the monsoon response by enhancing the westerly monsoon winds and thus the moisture influx from the North Atlantic. These inland regions thereby become increasingly connected with the oceanic moisture 

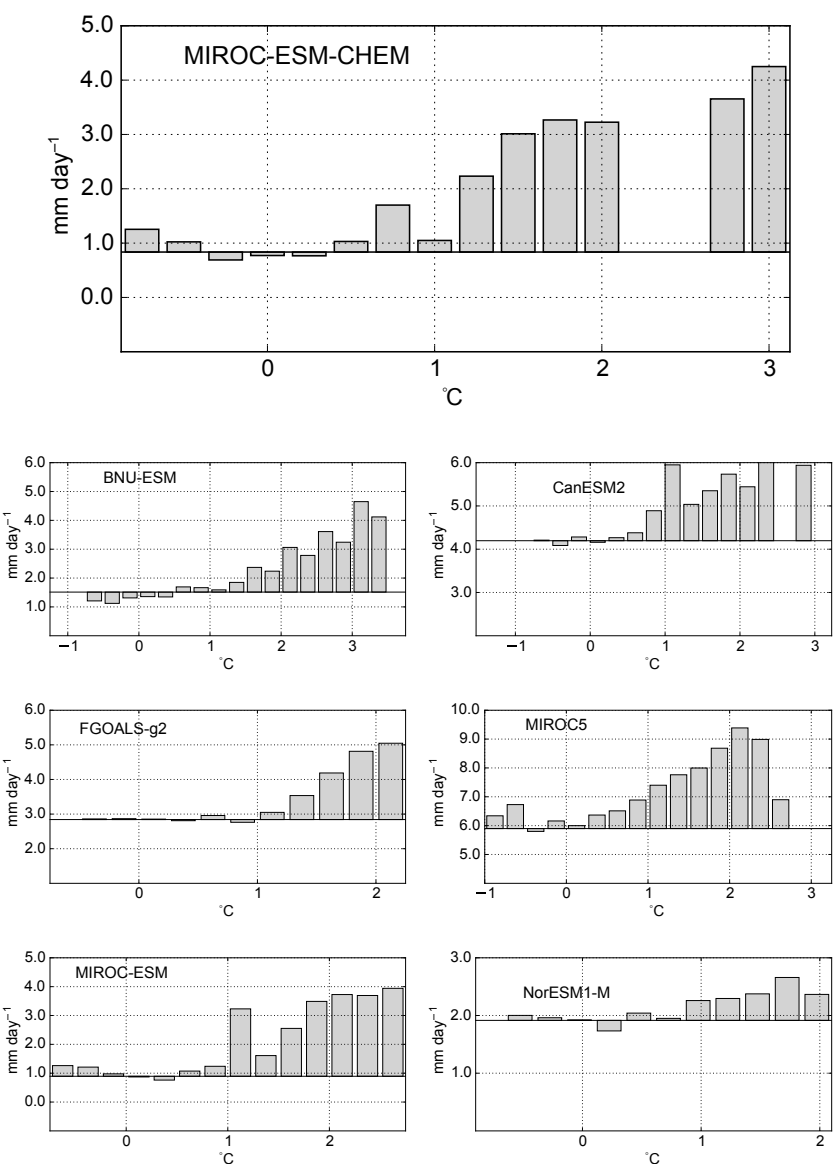

Figure 8. As Fig. 7 but for Mediterranean SST change.

source and benefit from further increases in oceanic evaporation.

This framework can explain the observed shape of the rainfall response in both the time and SST domains (Fig. 10): the functional form of the rainfall-SST relationship found in the Wet7 models (most prominently in MIROC-ESMCHEM) resembles the concave form and threshold behavior that arises from the above theory; given the convex form of mean SST forcing under global warming, the resulting pattern of rainfall over time is one where rainfall is relatively stable and low up to a certain point and then starts rising quasi-linearly.

\section{Discussion and conclusions}

This explanation of an abrupt intensification of inland monsoon rainfall in the Sahel region is consistent with studies suggesting a substantially wetter Sahel, and Sahara, region in past climates compared to today (DeMenocal et al., 2000; Gasse, 2000). It is also consistent with theories linking rainfall changes in the Sahel to a combination of a local (through radiative forcing changes) and a remote (through tropical SST impacts on atmospheric stability) forcing mechanism
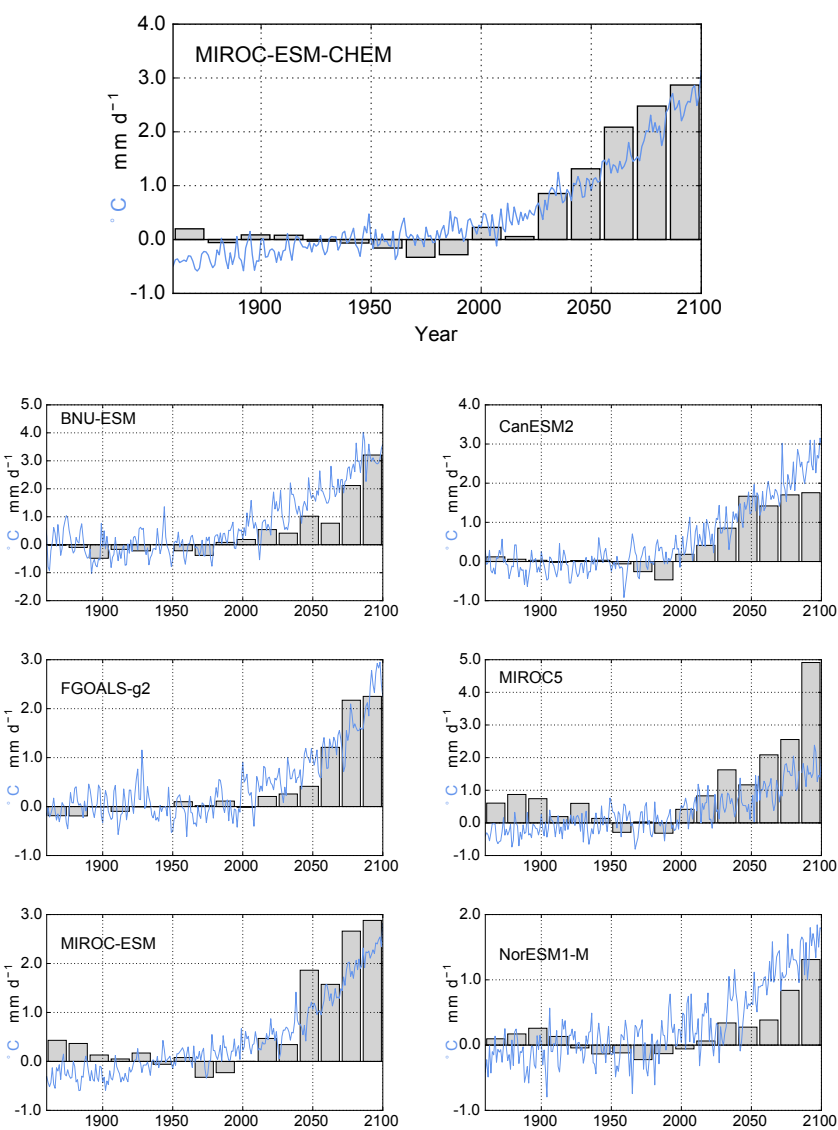

Figure 9. Mean Sahel July-September rainfall in 15-year intervals. Bars illustrate the deviation from the 1900-1999 rainfall average (horizontal black line), in $\mathrm{mm} \mathrm{day}^{-}{ }^{-}$. Blue line shows yearly JulySeptember tropical North Atlantic SST, in ${ }^{\circ} \mathrm{C}$ (same axis).

(Giannini, 2010; Giannini et al., 2013; Seth et al., 2010). In a warming world, the remote mechanism would increase atmospheric stability, especially in places with oceanic influence, and make it harder for convection to set in. Acting in the other direction, the local mechanism would directly warm the surface and decrease vertical stability over land. The mechanism we suggest here would act on top of these two mechanisms and help explain the abruptness of the Sahel rainfall response to global warming seen in some models. It would particularly affect the more continental parts of the region. We note that part of the increased moisture influx is through westerly winds near $10^{\circ} \mathrm{N}$, a flow called the West African westerly jet ( $\mathrm{Pu}$ and Cook, 2010, 2012). While its intraseasonal dynamics are somewhat distinct from the more southerly monsoon flow across the Gulf of Guinea, on a seasonal timescale both are driven by the pressure - and thus temperature - gradient between the eastern Atlantic and the Sahel and would be subject to the dynamical feedback mechanism described above. Our analysis also provides further evidence for the role of the Mediterranean Sea as a contributor to enhanced Sahelian moisture availability, which then further amplifies 

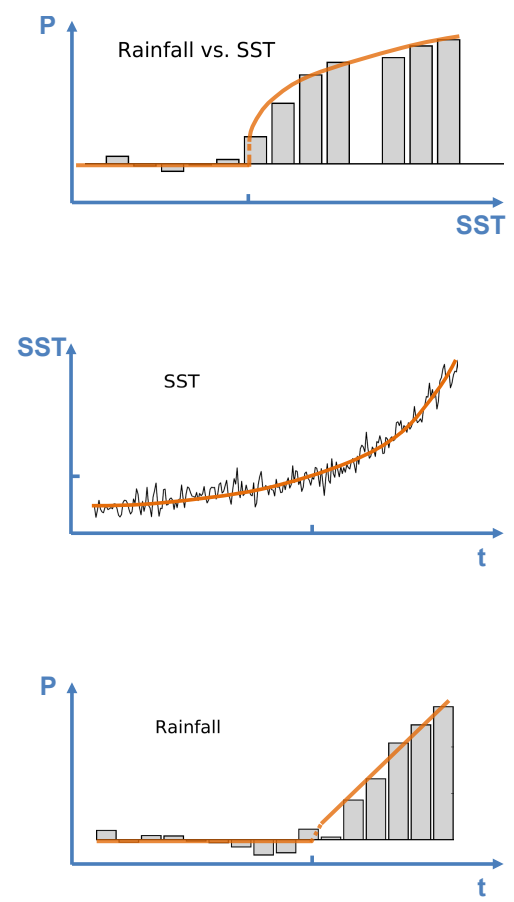

Figure 10. Comparison of model simulations with the concept of a monsoon threshold. Data are from the MIROC-ESM-CHEM simulation and are identical to the data shown in the top panels of Figs. 7 and 9; they are shown here without labels to emphasize the functional form. Orange lines (with blue axes) show illustrative functional forms that qualitatively match those of the simulation data and are consistent with analytical results from a minimal monsoon model (Schewe et al., 2012): the moisture-advection feedback implies that no continental monsoon exists below a certain threshold (blue tick mark) in the energy budget - here controlled by sea surface temperature (SST) - whereas above the threshold, monsoon intensity is a concave function of SST (top). In combination with a convex SST evolution (middle), this behavior can give rise to the observed rainfall evolution over time, where rainfall is relatively stable and low up to a certain point and then starts rising quasi-linearly.

inflow from the North Atlantic through latent heating over the Sahel.

We have found a strong, non-linear Sahel rainfall increase only in a minority of the CMIP5 models, and we do not mean to imply that these particular model simulations are more realistic than others. Consideration of the mechanism demonstrated here may, however, help to make sense of the diversity of model projections, and eventually establish a more consistent understanding of the Sahel's future climate in a warming world. We also note that the marked increase in Sahel rainfall begins at remarkably similar levels of SST change across the Wet7 models: mostly at around, or just below, $1{ }^{\circ} \mathrm{C}$ of SST warming (Fig. 7). In order to put these regional climatic changes in the context of global anthropogenic warming, we also show the projected Sahel rainfall changes over global mean temperature (GMT) change (Fig. 11). Given the different regional distribution of the warming signal in different
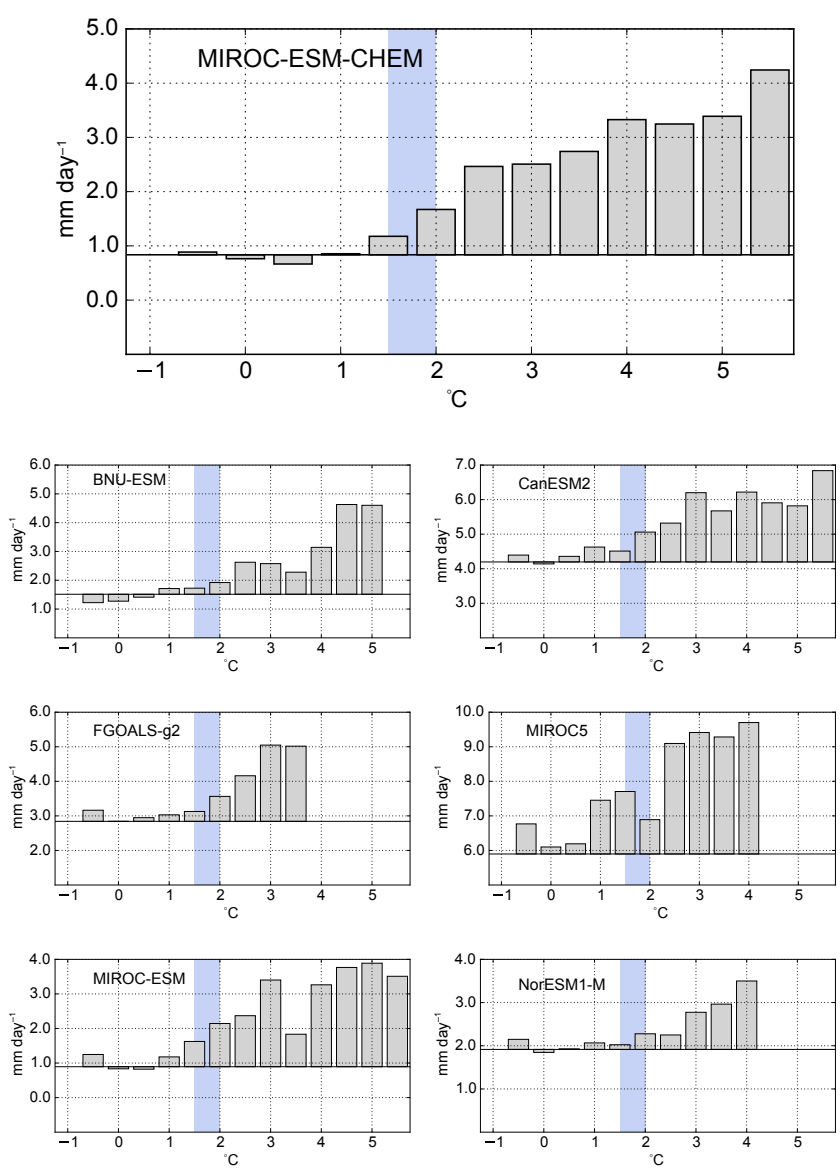

Figure 11. As Fig. 7, but with global mean temperature (GMT) change on the horizontal axis, instead of SST change. The blue shading marks the "Paris range", i.e., the global warming levels consistent with the United Nations' 2015 Paris Agreement (UNFCC, 2015).

models and the fact that GMT and SST do not necessarily co-vary on an annual timescale, there is not as clear an association of the rainfall change with GMT change as with SST change: the GMT level at which Sahel rainfall begins to increase strongly is somewhat different across the models. However, it may be noted that in many of the models the "Paris range" of $1.5-2.0^{\circ} \mathrm{C}$ of global warming (UNFCC, 2015) presents an approximate dividing line between the historical Sahel climate regime and a substantially wetter future climate.

Data availability. Simulation data were obtained from the CMIP5 archive at http://cmip-pcmdi.llnl.gov/cmip5/ (Taylor et al., 2012). 


\section{Appendix A: Models and data}

We analyzed simulations from the BNU-ESM, CanESM2, FGOALS-g2, MIROC-ESM-CHEM, MIROC5, MIROCESM, NorESM1-M (Wet7 subset), ACCESS1-0, ACCESS13, CESM1-BGC, CESM1-CAM5, CMCC-CM, CMCCCMS, CMCC-CESM, CNRM-CM5, EC-EARTH, FIOESM, GFDL-CM3, GFDL-ESM2M, GFDL-ESM2G, GISSE2-H, GISS-E2-R, HadGEM2-ES, HadGEM2-CC, inmcm4, IPSL-CM5A-LR, IPSL-CM5A-MR, IPSL-CM5B-LR, MRICGCM3, and MPI-ESM-MR global climate models (Supplement Table S1), driven by historical forcing and the RCP8.5 greenhouse gas concentration scenario (Taylor et al., 2012; Meinshausen et al., 2011). Where several realizations of the same model simulation were available, we used the r1ilp1 configuration, since this one was available from all models. Near-surface wind data were not available for FGOALS-g2; therefore, we show 850 mbar wind. CRU TS3.1 monthly precipitation data were obtained from http://badc.nerc.ac.uk. 


\section{The Supplement related to this article is available online at https://doi.org/10.5194/esd-8-495-2017-supplement.}

Author contributions. JS and AL designed the research. JS carried out the analysis and wrote the paper, with contributions from AL.

Competing interests. The authors declare that they have no conflict of interest.

Acknowledgements. We acknowledge the World Climate Research Programme's Working Group on Coupled Modelling, which is responsible for CMIP, and we thank the climate modeling groups for producing and making available their model output. Jacob Schewe received funding through the Leibniz Society's EXPACT project (SAW-2013-PIK-5).

Edited by: Rui A. P. Perdigão

Reviewed by: two anonymous referees

\section{References}

Biasutti, M.: Forced Sahel rainfall trends in the CMIP5 archive, J. Geophys. Res.-Atmos., 118, 1613-1623, https://doi.org/10.1002/jgrd.50206, 2013.

Biasutti, M. and Giannini, A.: Robust Sahel drying in response to late 20th century forcings, Geophys. Res. Lett., 33, L11706, https://doi.org/10.1029/2006GL026067, 2006.

DeMenocal, P., Ortiz, J., Guilderson, T., Adkins, J., Sarnthein, M., Baker, L., and Yarusinsky, M.: Abrupt onset and termination of the African Humid Period: rapid climate responses to gradual insolation forcing, Quat. Sci. Rev., 19, 347-361, 2000.

Dong, B. and Sutton, R.: Dominant role of greenhouse-gas forcing in the recovery of Sahel rainfall, Nat. Clim. Chang., 5, 757-760, https://doi.org/10.1038/nclimate2664, 2015.

Folland, C., Palmer, T., and Parker, D.: Sahel rainfall and worldwide sea temperatures, 1901-85, Nature, 320, 602-607, 1986.

Fontaine, B., Roucou, P., and Monerie, P.-A.: Changes in the African monsoon region at medium-term time horizon using 12 AR4 coupled models under the A1b emissions scenario, Atmos. Sci. Lett., 12, 83-88, https://doi.org/10.1002/asl.321, 2011.

Gasse, F.: Hydrological changes in the African tropics since the Last Glacial Maximum, Quat. Sci. Rev., 19, 189-211, 2000.

Giannini, A.: Mechanisms of Climate Change in the Semiarid African Sahel: The Local View, J. Climate, 23, 743-756, https://doi.org/10.1175/2009JCLI3123.1, 2010.

Giannini, A., Saravanan, R., and Chang, P.: Oceanic forcing of Sahel rainfall on interannual to interdecadal time scales, Science, 302, 1027-1030, https://doi.org/10.1126/science.1089357, 2003.

Giannini, A., Salack, S., Lodoun, T., Ali, A., Gaye, A. T., and Ndiaye, O.: A unifying view of climate change in the Sahel linking intra-seasonal, interannual and longer time scales, Environ. Res. Lett., 8, 024010, https://doi.org/10.1088/1748-9326/8/2/024010, 2013.
Gupta, A. K., Anderson, D. M., and Overpeck, J. T.: Abrupt changes in the Asian southwest monsoon during the Holocene and their links to the North Atlantic Ocean, Nature, 421, 354-357, 2003.

Harris, I., Jones, P., Osborn, T., and Lister, D.: Updated high-resolution grids of monthly climatic observations the CRU TS3.10 Dataset, Int. J. Climatol., 34, 623-642, https://doi.org/10.1002/joc.3711, 2014.

Herzschuh, U., Borkowski, J., Schewe, J., Mischke, S., and Tian, F.: Moisture-advection feedback supports strong early-to-mid Holocene monsoon climate on the eastern Tibetan Plateau as inferred from a pollen-based reconstruction, Palaeogeogr. Palaeoclimatol. Palaeoecol., 402, 44-54, https://doi.org/10.1016/j.palaeo.2014.02.022, 2014.

Lebel, T., Cappelaere, B., Vieux, B., Galle, S., Hanan, N., Kergoat, L., Levis, S., and Ali, A.: Recent trends in the Central and Western Sahel rainfall regime (1990-2007), J. Hydrol., 375, 52-64, 2009.

Levermann, A., Schewe, J., Petoukhov, V., and Held, H.: Basic mechanism for abrupt monsoon transitions., P. Natl. Acad. Sci. USA, 106, 20572-20577, https://doi.org/10.1073/pnas.0901414106, 2009.

Levermann, A., Petoukhov, V., Schewe, J., and Schellnhuber, H. J.: Abrupt monsoon transitions as seen in paleorecords can be explained by moisture-advection feedback, P. Natl. Acad. Sci. USA, E2348-E2349, https://doi.org/10.1073/pnas.1603130113, 2016.

McGee, D., DeMenocal, P., Winckler, G., Stuut, J., and Bradtmiller, L.: The magnitude, timing and abruptness of changes in North African dust deposition over the last 20,000 yr, Earth Planet. Sci. Lett., 371-372, 163-176, https://doi.org/10.1016/j.epsl.2013.03.054, 2013.

Meinshausen, M., Smith, S. J., Calvin, K., Daniel, J. S., Kainuma, M. L. T., Lamarque, J.-F., Matsumoto, K., Montzka, S. A., Raper, S. C. B., Riahi, K., Thomson, A., Velders, G. J. M., and Vuuren, D. P.: The RCP greenhouse gas concentrations and their extensions from 1765 to 2300, Clim. Change, 109, 213-241, https://doi.org/10.1007/s10584-011-0156-z, 2011.

Nicholson, S. E.: The West African Sahel: A Review of Recent Studies on the Rainfall Regime and Its Interannual Variability, ISRN Meteorol., 2013, 1-32, https://doi.org/10.1155/2013/453521, 2013.

Park, J.-Y., Bader, J., Matei, D., Patricola, C. M., and Knutson, T. R.: Northern-hemispheric differential warming is the key to understanding the discrepancies in the projected Sahel rainfall, Nat. Commun., 6, 5985, https://doi.org/10.1038/ncomms6985, 2015.

Park, J.-Y., Bader, J., and Matei, D.: Anthropogenic Mediterranean warming essential driver for present and future Sahel rainfall, Nat. Clim. Chang., 6, 941-945, https://doi.org/10.1038/nclimate3065, 2016.

Power, S. B., Delage, F., Colman, R., and Moise, A.: Consensus on Twenty-First-Century Rainfall Projections in Climate Models More Widespread than Previously Thought, J. Climate, 25, 3792-3809, https://doi.org/10.1175/JCLI-D-11-00354.1, 2012.

$\mathrm{Pu}$, B. and Cook, K. H.: Dynamics of the West African westerly jet, J. Climate, 23, 6263-6276, https://doi.org/10.1175/2010JCLI3648.1, 2010.

$\mathrm{Pu}, \mathrm{B}$. and Cook, K. H.: Role of the West African Westerly Jet in Sahel Rainfall Variations, J. Climate, 25, 2880-2896, https://doi.org/10.1175/JCLI-D-11-00394.1, 2012. 
Roehrig, R., Bouniol, D., Guichard, F., Hourdin, F., and Redelsperger, J.-L.: The Present and Future of the West African Monsoon: A Process-Oriented Assessment of CMIP5 Simulations along the AMMA Transect, J. Climate, 26, 6471-6505, https://doi.org/10.1175/JCLI-D-12-00505.1, 2013.

Rowell, D.: The impact of Mediterranean SSTs on the Sahelian rainfall season, J. Climate, 849-862, https://doi.org/10.1175/15200442(2003)016<0849:TIOMSO>2.0.CO;2, 2003.

Schewe, J., Levermann, A., and Cheng, H.: A critical humidity threshold for monsoon transitions, Clim. Past, 8, 535-544, https://doi.org/10.5194/cp-8-535-2012, 2012.

Seshadri, A. K.: Energetics and monsoon bifurcations, Clim. Dynam., 48, 1-16, https://doi.org/10.1007/s00382-016-3094-7, 2016.

Seth, A., Rauscher, S. A., Rojas, M., Giannini, A., and Camargo, S. J.: Enhanced spring convective barrier for monsoons in a warmer world?, Clim. Change, 104, 403-414, https://doi.org/10.1007/s10584-010-9973-8, 2010.

Sissoko, K., Keulen, H., Verhagen, J., Tekken, V., and Battaglini, A.: Agriculture, livelihoods and climate change in the West African Sahel, Reg. Environ. Chang., 11, 119-125, https://doi.org/10.1007/s10113-010-0164-y, 2010.

Tarhule, A.: Damaging Rainfall and Flooding: The Other Sahel Hazards, Clim. Change, 72, 355-377, https://doi.org/10.1007/s10584-005-6792-4, 2005.

Taylor, K. E., Stouffer, R. J., and Meehl, G. A.: An Overview of CMIP5 and the Experiment Design, B. Am. Meteorol. Soc., 93, 485-498, https://doi.org/10.1175/BAMS-D-1100094.1, 2012 (data available at: http://cmip-pcmdi.llnl.gov/ cmip5/).
Tschakert, P., Sagoe, R., Ofori-Darko, G., and Codjoe, S. N.: Floods in the Sahel: an analysis of anomalies, memory, and anticipatory learning, Clim. Change, 103, 471-502, https://doi.org/10.1007/s10584-009-9776-y, 2010.

UNFCC: Adoption of the Paris Agreement, available at: http://unfccc.int/paris_agreement/items/9485.php (last access: 19 June 2017), 2015.

van Vuuren, D. P., Edmonds, J., Kainuma, M., Riahi, K., Thomson, A., Hibbard, K., Hurtt, G. C., Kram, T., Krey, V., Lamarque, J. F., Masui, T., Meinshausen, M., Nakicenovic, N., Smith, S. J., and Rose, S. K.: The representative concentration pathways: An overview, Clim. Change, 109, 5-31, https://doi.org/10.1007/s10584-011-0148-z, 2011.

Wang, Y., Cheng, H., Edwards, R. L., Kong, X., Shao, X., Chen, S., Wu, J., Jiang, X., Wang, X., and An, Z.: Millennial- and orbital-scale changes in the East Asian monsoon over the past 224,000 years, Nature, 451, 1090-1093, https://doi.org/10.1038/nature06692, 2008.

Weldeab, S., Lea, D. W., Schneider, R. R., and Andersen, N.: 155,000 years of West African monsoon and ocean thermal evolution., Science, 316, 1303-7, https://doi.org/10.1126/science.1140461, 2007.

Zeng, N.: Atmospheric science. Drought in the Sahel., Science, 302, 999-1000, https://doi.org/10.1126/science.1090849, 2003. 